\title{
APPLICATION AND VERIFICATION OF A THREE-DIMENSIONAL HYDRODYNAMIC MODEL TO HAMILTON HARBOUR, CANADA
}

\author{
IOANNIS K. TSANIS* \\ JIAN WU**
}

*Department of Civil Engineering, McMaster University

Hamilton, Ontario, Canada L8S 4 L7

**J. E. Edinger Associates, Inc., 37 West Avenue, Wayne

Pennsylvania 19087-3226, U.S.A

Received: 02/08/99

Accepted: 22/03/00 *to whom all correspondence should be addressed e-mail: tsanis@water.eng.mcmaster.ca.

\begin{abstract}
A multi-layered three-dimensional hydrodynamic model has been developed to provide flow fields and water level changes in Hamilton Harbour. The field data collected in Hamilton Harbour during 1990 \& 1991 field seasons was used for model verification. The simulated currents were compared with current meter data. Results from the trajectory model are in good agreement with the drogue experimental data. A quantitative criterion to evaluate the trajectory comparison was established with the help of the trajectory model using the random-walk approach. By using the water level changes in the Burlington Ship Canal, the model predictions were validated with the measurements at three water level stations in the Harbour. These comparisons demonstrate that the models can simulate the major features of the water current and level changes in Hamilton Harbour.
\end{abstract}

KEY WORDS: Hydrodynamic Model, Trajectory Model, Model Verification, Hamilton Harbour

\section{INTRODUCTION}

Hamilton Harbour, located at the western end of Lake Ontario (Fig. 1), is one of forty areas of environmental concern in the Great Lakes. In recent years, many projects in the Harbour required a fine resolution hydrodynamic model so that the current structure can be simulated and used as an input to water quality and sediment transport models (MOE, 1992).

There were a limited number of studies conducted on modelling the current movements in the Harbour (MOE, 1974; Rasmussen and Badr, 1978; James and Eid, 1978). The two-dimensional models used by MOE (1974) and Rasmussen and Badr (1978) were unable to simulate the cur- rent structure in the vertical direction. A threedimensional model is necessary to simulate this phenomenon. In the three-dimensional model by James and Eid (1978), the non-linear horizontal advection terms were not included and the vertical eddy viscosity coefficient was taken as a constant, which is not realistic for the wind-induced flow (Tsanis, 1989). The coarse grid, i.e. 300 meter, used in all previous models was unable to describe in detail the shoreline. Furthermore, the model verification was insufficient. As a result, a high resolution model must be employed and detailed model verification is required.

The hydrodynamic model used to simulate the current distribution in Hamilton Harbour is a 
multi-layered stratified three-dimensional model. A sigma coordinate transformation is used in the vertical plane in the $3 \mathrm{D}$ model for a smoother representation of the bottom topography. A fractional step method is used to split the vertical diffusion terms from the rest of the momentum equations so that a semi-implicit scheme can be applied to offset the limit on the time step. A particle trajectory model that uses the random-walk approach is employed to simulate the trajectories of particles released in the Harbour.

Model verification using field data are a very important aspect in model application. Although a lot of data have been obtained in Hamilton Harbour (MOE, 1992), there is no existing model that utilized these data for verification purposes. An extensive field study was undertaken by the scientists at National Water Research Institute (NWRI) of Canadian Centre for Inland Waters (CCIW) during 1990 \& 1991 (Boyce and Chiocchio, 1991). The field data included currents from 17 current meters, trajectories from over 10 drogue experiments, and water levels from three water level gauges. The locations of these instruments are presented in Fig. 1. The features of the current and water level data are presented in Boyce and Chiocchio (1991) and Wu (1993) and Wu et al. (1996).

In this paper, two methods were used for model verification. The first method compares model results with field data in the time domain (pointby-point comparison). However, a quantitative verification of the model with current data is particularly difficult because a meaningful comparison of observed and computed vector quantities must involve both direction and magnitude. The comparison depends on the location of a station and its meter depth because the current meter is sometimes located in a region of flow reversal, whereas in other cases, the meter is located in a region of unidirectional current. The second method compares simulated trajectories with the field measurements (spatial comparison). This method is easily visualized and can be statistically evaluated.

\section{MATHEMATICAL MODELS} Three-Dimensional Hydrodynamic Model

A sigma stretched coordinate

$$
\sigma=(z-\zeta(x, y, t)) /(h(x, y)+\zeta(x, y, t))
$$

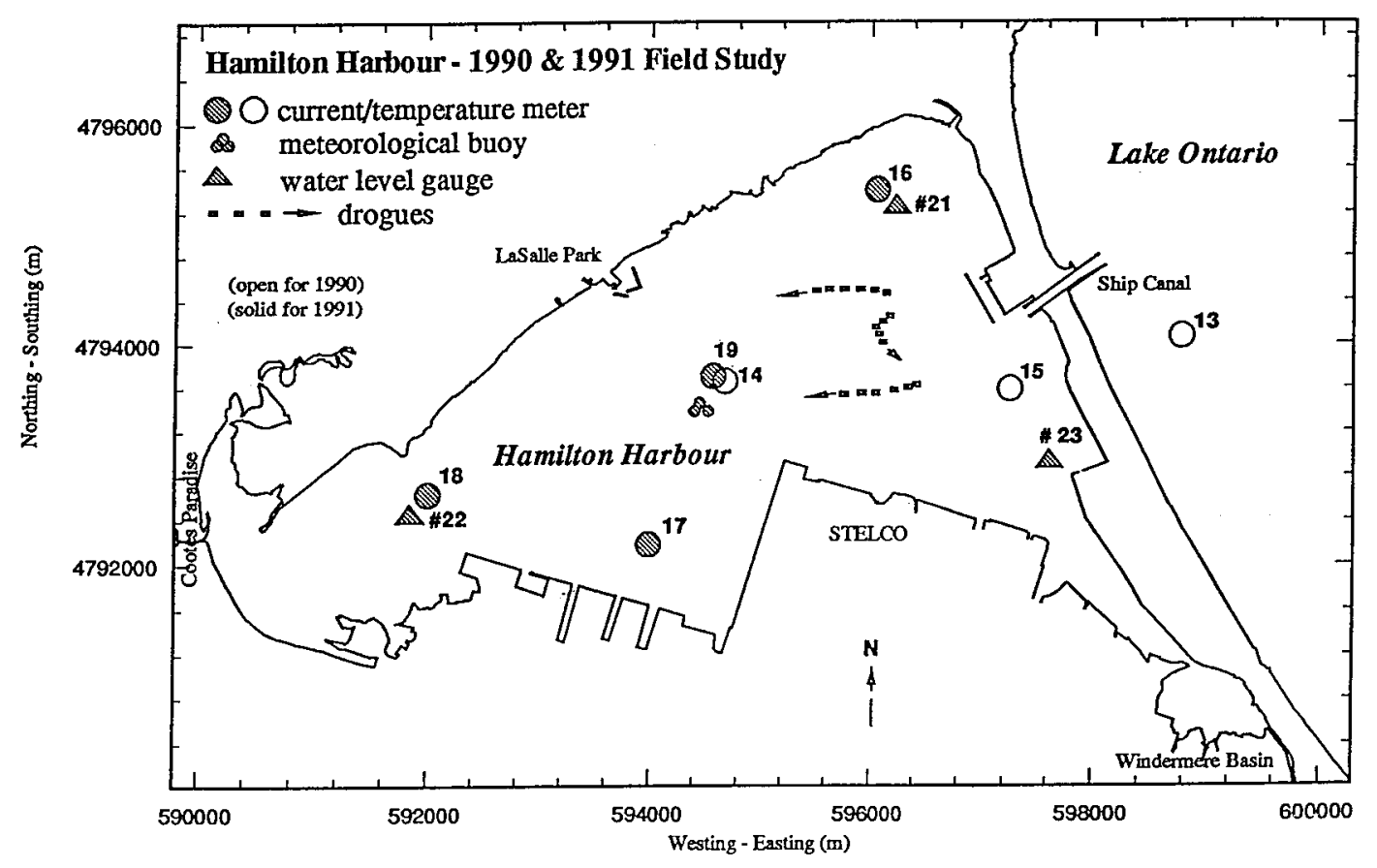

Figure 1. Locations of meteorological and limnological observation stations in Hamilton Harbour during the 1990 and 1991 field study seasons. 
is used in the three-dimensional model in which the free surface and bottom topography were mapped onto the coordinate surface. Thus, the layer number is constant over the whole basin. The model equations in the system are:

$$
\begin{aligned}
& \frac{\partial u}{\partial t}+u \frac{\partial u}{\partial x}+v \frac{\partial u}{\partial y}+\omega \frac{\partial u}{\partial \sigma}=f v-g \frac{\partial \zeta}{\partial x}+B_{x} \\
& +\tau_{u}+\frac{1}{H} \frac{\partial}{\partial \sigma}\left(\frac{K_{v}}{H} \frac{\partial u}{\partial \sigma}\right)
\end{aligned}
$$

$$
\begin{aligned}
& \frac{\partial v}{\partial t}+u \frac{\partial v}{\partial x}+v \frac{\partial v}{\partial y}+\omega \frac{\partial v}{\partial \sigma}=-f u-g \frac{\partial \zeta}{\partial y}+ \\
& +B_{y}+\tau_{v}+\frac{1}{H} \frac{\partial}{\partial \sigma}\left(\frac{K_{v}}{H} \frac{\partial v}{\partial \sigma}\right)
\end{aligned}
$$

$\frac{\partial P}{\partial \sigma}=-\varrho g H$

$\frac{\partial \zeta}{\partial \mathrm{t}}+\frac{\partial \mathrm{Hu}}{\partial \mathrm{x}}+\frac{\partial \mathrm{Hv}}{\partial \mathrm{y}}+\frac{\partial \omega}{\partial \sigma}=0$

$\frac{\partial \mathrm{T}}{\partial \mathrm{t}}+\mathrm{u} \frac{\partial \mathrm{T}}{\partial \mathrm{x}}+\mathrm{v} \frac{\partial \mathrm{T}}{\partial \mathrm{y}}+\omega \frac{\partial \mathrm{T}}{\partial \sigma}=$

$=\tau_{\mathrm{T}}+\frac{1}{\mathrm{H}} \frac{\partial}{\partial \sigma}\left(\frac{\mathrm{N}_{\mathrm{v}}}{\mathrm{H}} \frac{\partial \mathrm{T}}{\partial \sigma}\right)$

where $\omega$ is the vertical velocity component in $\sigma$ coordinates, as

$$
\begin{aligned}
& \omega=\frac{w}{H}-\frac{u}{H}\left(\sigma \frac{\partial H}{\partial x}+\frac{\partial \zeta}{\partial x}\right)- \\
& -\frac{v}{H}\left(\sigma \frac{\partial H}{\partial y}+\frac{\partial \zeta}{\partial y}\right)-\frac{1}{H}\left(\sigma \frac{\partial H}{\partial t}+\frac{\partial \zeta}{\partial t}\right)
\end{aligned}
$$

$h$ is the water depth; $\zeta$ is the super elevation above the still water surface; $H=h+\xi$ is the total water depth; $u$ and $v$ are the horizontal velocity components in the $\mathrm{x}$ - and $\mathrm{y}$ - directions respectively; $\mathrm{T}$ is the water temperature; $f=2 \Omega \sin (\varphi)$ is the Coriolis coefficient; $\varphi$ is the geographic latitude of the domain and $\Omega$ is the angular rotation of the Earth; $K_{v}$ is the vertical diffusivity coefficient of momentum; $N_{v}$ is the vertical thermal diffusivity coefficient; $\omega$ is the vertical velocity component in sigma coordinates; $\tau_{u}, \tau_{v}$ and $\tau_{T}$ are the horizontal eddy diffusivity terms in the sigma coordinates for momentum and heat respectively;

$$
\begin{gathered}
\tau_{\mathrm{u}}=\frac{1}{\mathrm{H}} \frac{\partial \mathrm{H} \tau_{\mathrm{x}}}{\partial \mathrm{x}}-\frac{1}{\mathrm{H}} \frac{\partial}{\partial \sigma}\left[\left(\sigma \frac{\partial \mathrm{H}}{\partial \mathrm{x}}+\frac{\partial \zeta}{\partial \mathrm{x}}\right) \tau_{\mathrm{x}}\right]- \\
-\frac{1}{\mathrm{H}} \frac{\partial \mathrm{H} \tau_{\mathrm{y}}}{\partial \mathrm{y}}-\frac{1}{\mathrm{H}} \frac{\partial}{\partial \sigma}\left[\left(\sigma \frac{\partial \mathrm{H}}{\partial \mathrm{y}}+\frac{\partial \zeta}{\partial \mathrm{x}}\right) \tau_{\mathrm{y}}\right]
\end{gathered}
$$

where,

$$
\begin{gathered}
\tau_{\mathrm{x}}=\mathrm{K}_{\mathrm{h}}\left[\frac{\partial \mathrm{u}}{\partial \mathrm{x}}-\frac{1}{\mathrm{H}} \frac{\partial \mathrm{u}}{\partial \sigma}\left(\sigma \frac{\partial \mathrm{H}}{\partial \mathrm{x}}+\frac{\partial \zeta}{\partial \mathrm{x}}\right)\right] \\
\tau_{\mathrm{y}}=\mathrm{K}_{\mathrm{h}}\left[\frac{\partial \mathrm{u}}{\partial \mathrm{y}}-\frac{1}{\mathrm{H}} \frac{\partial \mathrm{u}}{\partial \sigma}\left(\sigma \frac{\partial \mathrm{H}}{\partial \mathrm{y}}+\frac{\partial \zeta}{\partial \mathrm{y}}\right)\right]
\end{gathered}
$$

where $K_{h}$ is the horizontal diffusivity coefficient of momentum and similar formulas can be derived for the $\tau_{v}$ and $\tau_{T} ; \mathrm{B}_{x}$ and $\mathrm{B}_{y}$ are the atmospheric pressure gradients and density gradients due to the temperature differences:

$$
\begin{aligned}
& \mathrm{B}_{\mathrm{x}}=-\frac{1}{\varrho_{0}} \frac{\partial \mathrm{P}_{\alpha}}{\partial \mathrm{x}}-\frac{\mathrm{g}}{\varrho_{0}} \frac{\partial}{\partial \mathrm{x}}\left(\mathrm{H} \int_{\sigma}^{0} \varrho d \sigma\right)-\mathrm{g} \sigma \frac{\partial \mathrm{H}}{\partial \mathrm{x}} \\
& \mathrm{B}_{\mathrm{y}}=-\frac{1}{\varrho_{0}} \frac{\partial \mathrm{P}_{\alpha}}{\partial \mathrm{y}}-\frac{\mathrm{g}}{\varrho_{0}} \frac{\partial}{\partial \mathrm{y}}\left(\mathrm{H} \int_{\sigma}^{0} \varrho d \sigma\right)-\mathrm{g} \sigma \frac{\partial \mathrm{H}}{\partial \mathrm{y}}
\end{aligned}
$$

where $P_{a}$ is the atmospheric pressure and $\varrho_{o}$ is the constant reference density. The equation of state for lake fresh water, relating the temperature to density, is given as

$$
\varrho=\varrho_{4}\left(1-\alpha \delta \mathrm{T}^{2}\right)
$$

where, $\alpha=6.8 \times 10^{6}{ }^{\circ} \mathrm{C}^{-2}$ is the constant; $\varrho_{4}$ is the water density at $4{ }^{\circ} \mathrm{C} ; \delta T=T-T_{4}$ is the temperature deviation from $4{ }^{\circ} \mathrm{C}$. The characteristic length in the vertical direction is two to three orders of magnitude smaller than the characteristic horizontal dimension. Therefore, the assumption of hydrostatic pressure distribution is valid and this is reflected in Eq. (4).

A fractional step method was used to split the ver- 
tical diffusivity terms from Eqs. (2) and (3). An explicit scheme was used for the advection and pressure gradient terms whereas an implicit scheme was used for the vertical viscosity terms to offset the small time step limit needed for stability in the explicit scheme. The atmospheric pressure term is not included in the model since Hamilton Harbour is a small water body. The detailed scheme is presented in Wu (1993) and $\mathrm{Wu}$ and Tsanis (1995).

The simulation starts with zero current and zero super-elevation. The temperature is set from the field measurements. The kinematic boundary conditions apply at the surface and bottom with the quadratic formulae relating the shear stresses with the wind velocity and the bottom velocity.

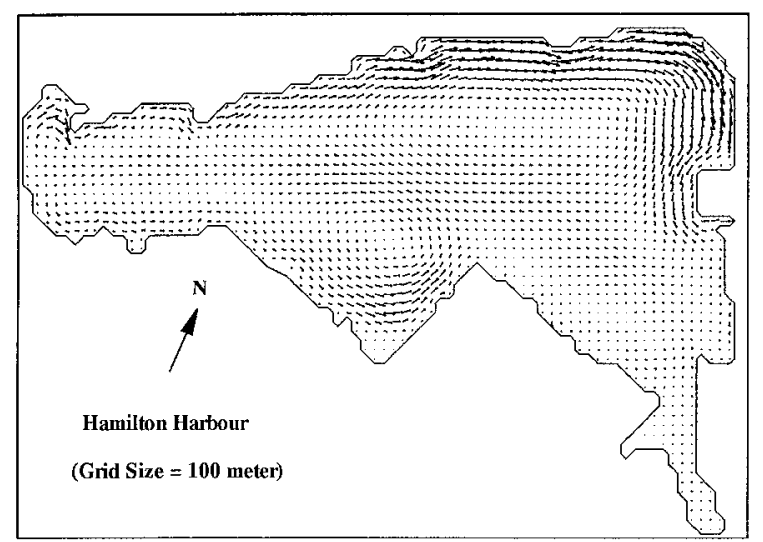

Figure 2. Circulation pattern in a high resolution (100 $\mathrm{m}$ grid) under a $5 \mathrm{~m} \mathrm{~s}^{-1}$ west wind in Hamilton Harbour.
The surface wind stress coefficient is 0.0013 and the bottom drag coefficient is 0.0025 . The vertical diffusivity coefficient of momentum $\mathrm{K}_{\mathrm{v}}=0.01 \mathrm{~m}^{2}$ $\mathrm{s}^{-1}$ and the horizontal diffusivity coefficient had values between 1 to $5 \mathrm{~m}^{2} \mathrm{~s}^{-1}$ that were used for model calibration. The lateral conditions include no normal fluxes of momentum and heat at the land shoreline except where there are inflows or outflows. All the boundary conditions are transformed into the forms of $\sigma$ coordinates using the appropriate operator transformation (Wu, 1993). A high resolution horizontal grid of $100 \mathrm{~m}$ and 5 layers in the vertical plane are used for Hamilton Harbour. The 5 layers are in sigma co-ordinates, i.e., layer depths change with the total depth and are kept the same during all simulations. The system is rotated 23.8 degrees clockwise from the north, to better represent the eastern and northeastern shorelines. The horizontal and vertical current distributions under a $5 \mathrm{~m} \mathrm{~s}^{-1}$ west wind in Hamilton Harbour are shown in Figs. 2 and 3.

\section{A Particle Trajectory Model}

Determination of oil or powerless vessel movement is required in the case of an oil spill or vessel rescue emergency in the marine and Great Lakes environment. Experiments using drogue and satellite drifters have been employed recently to determine the current structure in lakes (Murthy et al., 1986; Wu et al., 1987; Tsanis et al., 1990; Boyce and Chiocchio, 1991). After the currents have been obtained from the circulation model, it is straightforward to formulate a trajec-

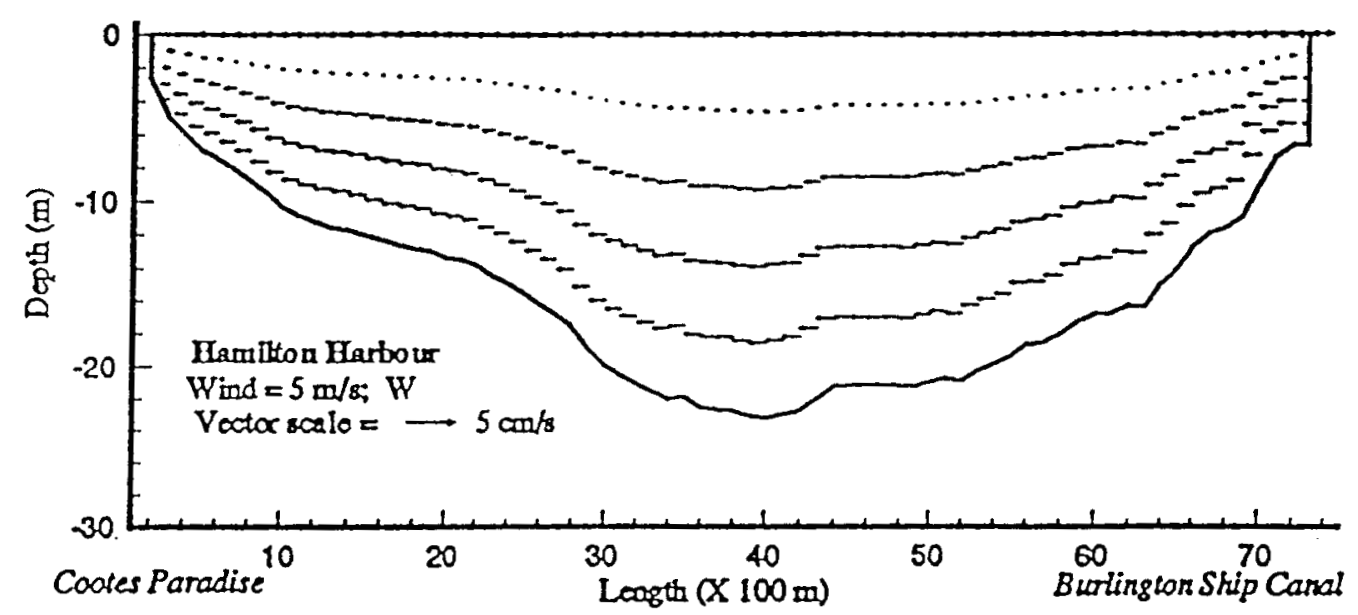

Figure 3. Circulation pattern in a vertical section from the Cootes Paradise to the Ship under a $5 \mathrm{~m} \mathrm{~s}^{-1}$ west wind in Hamilton Harbour. 
tory model. However, particle trajectories are not uniquely defined by the local velocity field and may be affected by turbulence and diffusion, as in the case of pollutant dispersion (due to the subgrid scale processes). These processes are not simulated in the circulation model. Dispersion can be simulated using a Monte-Carlo randomwalk approach. The random displacement evaluated by random numbers and horizontal dispersion coefficients are added to the movement computed from the flow field (Leendertse and Liu, 1977; Koutitas and Gousidou-Koutita, 1986). The equations governing the current-induced particle motions are:

$$
\frac{\partial \mathrm{X}}{\partial \mathrm{t}}=\mathrm{u}(\mathrm{x}, \mathrm{y}) ; \frac{\partial \mathrm{Y}}{\partial \mathrm{t}}=\mathrm{v}(\mathrm{x}, \mathrm{y})
$$

where $\mathrm{X}$ and $\mathrm{Y}$ are the particles' coordinates; and $\mathrm{u}$ and $\mathrm{v}$ are the velocity components at the depth where the particle is located. A second-order finite difference scheme can be applied to numerically evaluate the above equations (Bennett and Clites, 1987). By using the random-walk approach, the numerical scheme for the trajectory model then can be written as:

$$
\begin{aligned}
& \mathrm{X}^{\mathrm{n}+1}=\mathrm{X}^{\mathrm{n}}+\mathrm{u}\left(\mathrm{X}^{\mathrm{n}}, \mathrm{Y}^{\mathrm{n}}\right) \Delta \mathrm{t}+ \\
& +\frac{1}{2} \frac{\partial \mathrm{u}}{\partial \mathrm{x}}\left(\mathrm{X}^{\mathrm{n}+1}-\mathrm{X}^{\mathrm{n}}\right) \Delta \mathrm{t}+ \\
& +\frac{1}{2} \frac{\partial \mathrm{u}}{\partial \mathrm{y}}\left(\mathrm{Y}^{\mathrm{n}+1}-\mathrm{Y}^{\mathrm{n}}\right) \Delta \mathrm{t}+\mathrm{r}_{1} \sqrt{6 \Delta \mathrm{tK}_{\mathrm{h}}} \\
& \mathrm{Y}^{\mathrm{n}+1}=\mathrm{Y}^{\mathrm{n}}+\mathrm{v}\left(\mathrm{X}^{\mathrm{n}}, \mathrm{Y}^{\mathrm{n}}\right) \Delta \mathrm{t}+ \\
& +\frac{1}{2} \frac{\partial \mathrm{v}}{\partial \mathrm{x}}\left(\mathrm{X}^{\mathrm{n}+1}-\mathrm{X}^{\mathrm{n}}\right) \Delta \mathrm{t}+ \\
& +\frac{1}{2} \frac{\partial \mathrm{v}}{\partial \mathrm{y}}\left(\mathrm{Y}^{\mathrm{n}+1}-\mathrm{Y}^{\mathrm{n}}\right) \Delta \mathrm{t}+\mathrm{r}_{2} \sqrt{6 \Delta \mathrm{tK}}
\end{aligned}
$$

where the velocities $u, v$ and their derivatives at time level $n$ are computed using a bilinear interpolation scheme. The slipping factor (resistance to the water) and/or windage factor (resistance to the wind) may be considered in the individual application (Schwab et al., 1989). $r_{1}$ and $r_{2}$ are a pseudo-Gaussian random numbers with a mean of zero and a standard derivation of unity. According to the drogue experiments in Lake Tai, the horizontal dispersion coefficients have values between 0.1 to $1.0 \mathrm{~m}^{2} \mathrm{~s}^{-1}$ (Wu et al., 1987). The values for Lake Erie are between 1 to $10 \mathrm{~m}^{2} \mathrm{~s}^{-1}$ (Elzawahry, 1985).

\section{VERIFICATION WITH CURRENT METER DATA}

Current data from current meters were collected during the 1990 and 1991 field seasons in Hamilton Harbour. The simulated currents at five mooring meter locations - \#16d5m (location 16 depth 5 meters), \#17d5m, \#18d5m, \#19d6m and \#19d10m (Fig. 1) were compared with the measured data. The comparisons were made using the point-by-point method and three statistical criteria were used to evaluate the degree of agreement between the simulated and measured data.

The scenario, HH910717, was a three-day event, from 16:00 July 16 to $14: 00$ July 19, 1991. The wind directions were between 210 to 310 degrees, and the maximum wind speed reached $9.3 \mathrm{~m} \mathrm{~s}^{-1}$ on July 17. A comprehensive water quality measurement effort was undertaken at 22 stations in the Harbour (MOE, 1992). Temperature profiles were obtained at these stations from which an initial temperature field for the 3D stratified model was interpolated. During this period, the temperatures were quite uniform within the top $5 \mathrm{~m}$ of the water column depth at $24{ }^{\circ} \mathrm{C}$ and below the 20 $\mathrm{m}$ depth. A large gradient existed between the $5 \mathrm{~m}$ to $15 \mathrm{~m}$ depth, where the temperature difference was about $12{ }^{\circ} \mathrm{C} \quad\left(1.2^{\circ} \mathrm{C} \mathrm{m}^{-1}\right)$. This is a typical temperature profile in the Harbour during the summer season.

The following statistical criteria (Schwab et al., 1989) were used to evaluate the above comparisons: (1) $\alpha_{1}$ represents the ratio of the energy in the time-variable part of the current to the total energy in the observed current:

$$
\alpha_{1}=\frac{\sum\left[\left(\mathrm{u}_{0}-\overline{\mathrm{u}}_{0}\right)^{2}+\left(\mathrm{v}_{0}-\overline{\mathrm{v}}_{0}\right)^{2}\right]}{\sum\left(\mathrm{u}_{0}^{2}+\mathrm{v}_{0}^{2}\right)}
$$

where $\left(u_{0}, v_{0}\right)$ are the eastward and northward components of the observed currents and $\left(\bar{u}_{0}, \bar{v}_{0}\right)$ are their averaged values; (2) $\alpha_{2}$ compares the differences between observed and computed values $\left(u_{\mathrm{c}}, v_{\mathrm{c}}\right)$ for the total flows:

$$
\alpha_{2}=\frac{\sum\left[\left(\mathrm{u}_{0}-\mathrm{u}_{\mathrm{c}}\right)^{2}+\left(\mathrm{v}_{0}-\mathrm{v}_{\mathrm{c}}\right)^{2}\right]}{\sum\left(\mathrm{u}_{0}^{2}+\mathrm{v}_{0}^{2}\right)}
$$


Table 1. Comparison of observed and calculated currents in Hamilton Harbour (HH910717 - 16:00 16 - 16:00 19 July, 1991)

\begin{tabular}{|cccccc|}
\hline & Ratio & \#16d5m & \#17d5m & \#19d6m & \#19d10m \\
\hline 3D & $\alpha_{1}$ & 0.96 & 0.99 & 0.93 & 0.96 \\
\hline$\alpha_{2}$ & 2.22 & 1.21 & 2.81 & 1.65 \\
\hline$\alpha_{3}$ & 1.07 & 0.54 & 1.53 & 0.64 \\
\hline
\end{tabular}

and (3) $\alpha_{3}$ is the ratio of the root mean square value of the computed currents to the root mean square value of the observed currents:

$$
\alpha_{3}=\frac{\sqrt{\sum\left(\mathrm{u}_{\mathrm{c}} \mathrm{u}_{\mathrm{c}}+\mathrm{v}_{\mathrm{c}} \mathrm{v}_{\mathrm{c}}\right)}}{\sqrt{\sum\left(\mathrm{u}_{0} \mathrm{u}_{0}+\mathrm{v}_{0} \mathrm{v}_{0}\right)}}
$$

A large value of $\alpha_{1}$ means that the currents are highly time-dependent or time-variable. The ideal match between model and field data is achieved when $\alpha_{2}=0$ and $\alpha_{3}=1$. The statistical comparison between computed and measured currents is listed in Table 1. It can be seen that almost all the energy is in the time-variable current because $\alpha_{1}$ exceeds 0.95 at all stations. The value of $\alpha_{2}$ is about 1.21 to 2.81 and $\alpha_{3}$ ranges from 0.54 to 1.53 . In general, the model verification point-by-point with the current meter data is satisfactory for some current meters. The spatial limitation of the numerical grid and the location of the current meters close to the thermocline consist two reasons for the unsatisfactory agreement between field and simulated data. Furthermore, the wind field over Hamilton Harbour was assumed to be uniform in the model due to lack of spatial wind data. The spatial variability of the wind field that was not accounted in the model can alter significantly the magnitude and direction of the currents.

\section{VERIFICATION WITH DROGUE DATA}

There were over ten drogue experiments conducted during the 1990 field season. The drogue experimental data provide an excellent opportunity to verify the three-dimensional circulation model because the comparison is easily visualized and statistically verified.

The locations for each drogue in the Harbour's grid of the northing and easting in meters were first converted into the model grid system (rotated 23.8 degrees clockwise from the North). For comparison sake, the data interpolated had the same start and end time and the same time interval (half hour in this study) for all the drogues in each experiment. The 100 meter grid of Hamilton Harbour was used in the coupled circulation and trajectory prediction model. Hourly wind speed and direction were used as an input to the model. Because the drogues were deployed at either $2 \mathrm{~m}$ or $5 \mathrm{~m}$ below the water surface (the water depth is about $10 \mathrm{~m}-20 \mathrm{~m}$ ), the drogue movements represented the currents in the upper layer. Each experiment lasted for less than 5 hours. As a result, the change in Harbour's thermal structure could be ignored and the thermal stratification had only an effect on the vertical viscosity and baroclinic terms in the fully $3 \mathrm{D}$ model. The current fields at $2 \mathrm{~m}$ and $5 \mathrm{~m}$ below the water surface, which were the depths for the drogues, were interpolated from multi-layered current fields. The trajectories for each drogue were predicted using the trajectory model without the randomwalk term in each time step (a time step of 4 seconds was used in the numerical model), while only recorded at half hour intervals.

The drift velocity $v_{d}$ is assumed to be the sum of the current velocity $\mathrm{v}_{\mathrm{c}}$ and an unknown windage, i.e.,

$$
\mathrm{v}_{\mathrm{d}}=\mathrm{v}_{\mathrm{c}}+\alpha \mathrm{v}_{\mathrm{w}}
$$

where $\mathrm{v}_{\mathrm{w}}$ is the wind velocity and $\alpha$ is the windage factor. A least squares procedure was used to determine the optimal value of the windage factor. For statistical comparison purposes, the following ratios were designed (Schwab et al., 1989): $\gamma_{1}$ is the ratio of the variance of the difference between the observed drogue velocities $\left(u_{d}, v_{d}\right)$ and the computed current velocities $\left(u_{c}, v_{c}\right)$ to the variance of the observed drogue velocities; $\gamma_{2}$ is the ratio of the variance of the difference between the observed drogue velocities and the wind velocities multiplied by windage factor to the variance of the observed drogue velocities; $\gamma_{3}$ is the ratio of the variance of the difference between the observed drogue velocities and the combined 

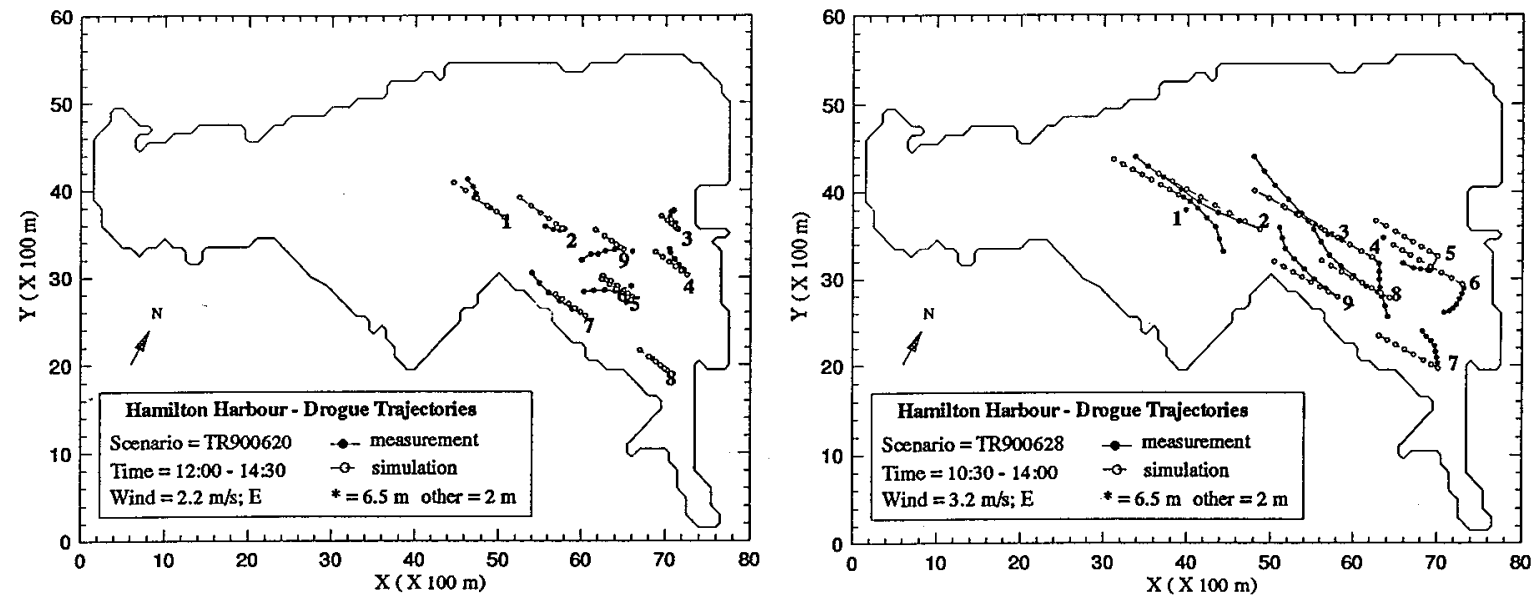

Figure 4. The measured (solid line with solid circle) and the simulated (dashed line with open circle) drogue trajectories for: (a) TR900620, (b) TR900628, in Hamilton Harbour.
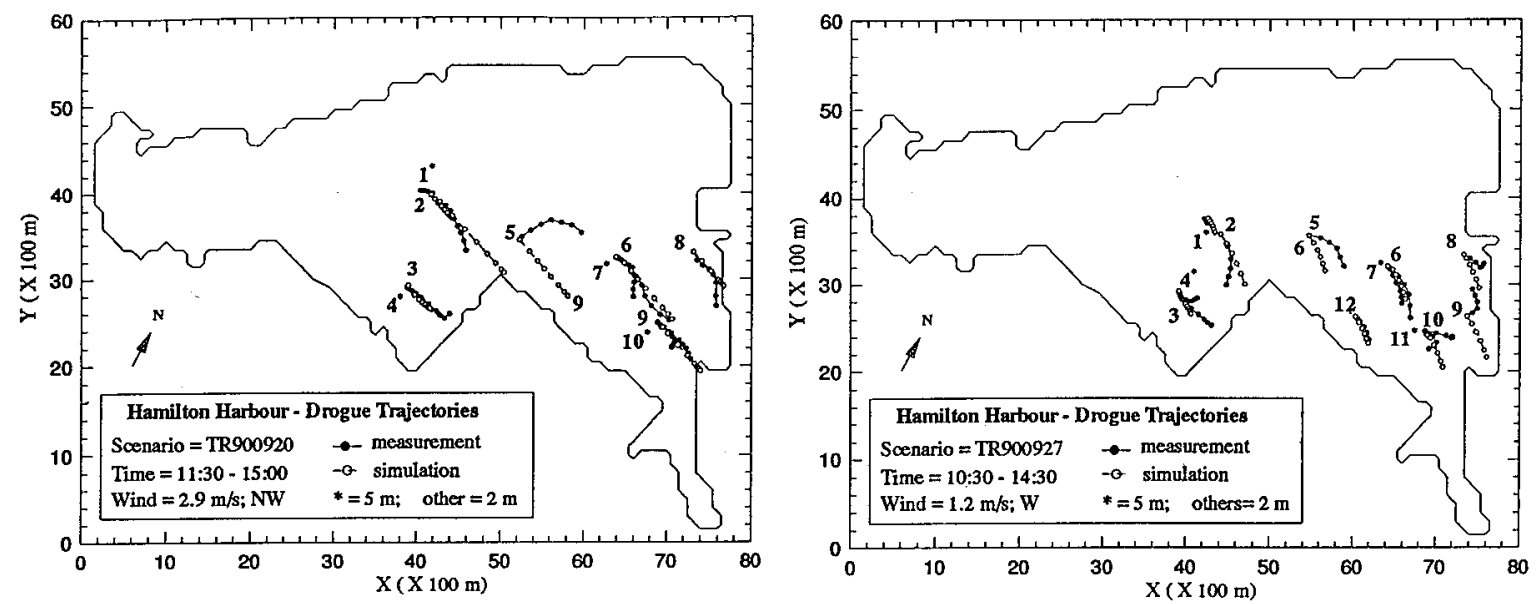

Figure 5. The measured (solid line with solid circle) and the simulated (dashed line with open circle) drogue trajectories for: (a) TR900920, (b) TR900927, in Hamilton Harbour.
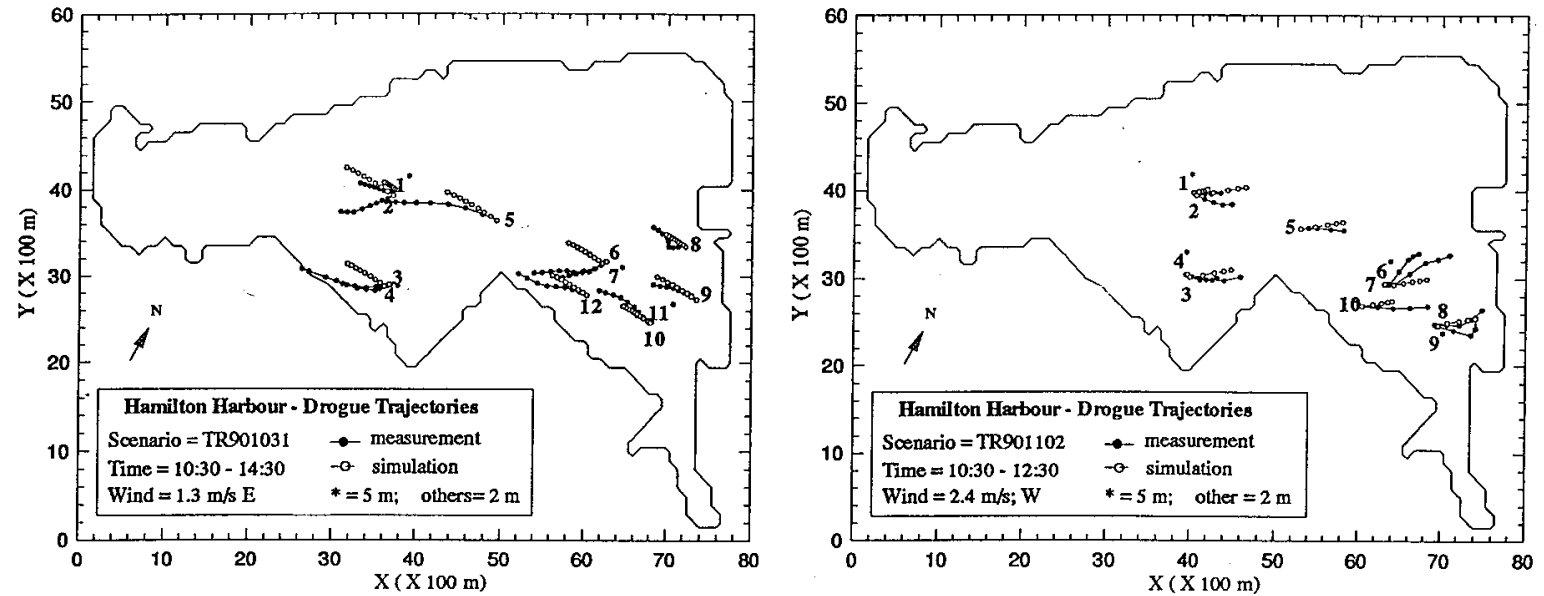

Figure 6. The measured (solid line with solid circle) and the simulated (dashed line with open circle) drogue trajectories for: (a) TR901031, (b) TR901102, in Hamilton Harbour. 
computed velocity (current plus windage) to the variance of the observed drogue velocities; i.e.,

$$
\gamma_{1}=\frac{\sum\left[\left(\mathrm{u}_{\mathrm{d}}-\mathrm{u}_{\mathrm{c}}\right)^{2}+\left(\mathrm{v}_{\mathrm{d}}-\mathrm{v}_{\mathrm{c}}\right)^{2}\right]}{\sum\left(\mathrm{u}_{\mathrm{d}}^{2}+\mathrm{v}_{\mathrm{d}}^{2}\right)}
$$

$\gamma_{2}=\frac{\sum\left[\left(\mathrm{u}_{\mathrm{d}}-\alpha \mathrm{u}_{\mathrm{w}}\right)^{2}+\left(\mathrm{v}_{\mathrm{d}}-\alpha \mathrm{v}_{\mathrm{w}}\right)^{2}\right]}{\sum\left(\mathrm{u}_{\mathrm{d}}^{2}+\mathrm{v}_{\mathrm{d}}^{2}\right)}$

$$
\gamma_{3}=\frac{\sum\left[\left(\mathrm{u}_{\mathrm{d}}-\mathrm{u}_{\mathrm{c}}-\alpha \mathrm{u}_{\mathrm{w}}\right)^{2}+\left(\mathrm{v}_{\mathrm{d}}-\mathrm{v}_{\mathrm{c}}-\alpha \mathrm{v}_{\mathrm{w}}\right)^{2}\right]}{\sum\left(\mathrm{u}_{\mathrm{d}}^{2}+\mathrm{v}_{\mathrm{d}}^{2}\right)}
$$

Six scenarios were selected from 1990 field experiments. Figs. 4, 5 and 6 show the observed drogue trajectories (solid line, solid circle) and the predicted trajectories (dashed line, open circle), along with the duration, mean wind velocity and direction. The statistical comparisons are shown in Tables 2 and 3, in which the averaged velocities derived from trajectories for both field and model data, windage $\alpha$, and ratios $\gamma_{1}, \gamma_{2}, \gamma_{3}$ are listed for each drogue in each scenario. No attempt is made to analyse all scenarios. Only two of them are presented in detail. In the scenario TR900620 (on June 20, 1990), nine drogues were released in the southeastern basin of Hamilton Harbour. Among them, seven drogues were deployed at $2 \mathrm{~m}$ below the surface and two drogues at $6.5 \mathrm{~m}$. Winds were about 1.2 to $1.9 \mathrm{~m} \mathrm{~s}^{-1}$ from 213 to 216 degrees clockwise from the north (a very weak wind condition). In general, all drogues followed the wind direction and a slight deflection for the drogues released at the $6.5 \mathrm{~m}$ depth. The speed ranged from 2 to $4 \mathrm{~cm} \mathrm{~s}^{-1}$. The computed trajectories were quite close to the observed trajectories for drogues $\# 1$, \#4, \#5, and the ratio of variance of difference $\left(\gamma_{1}\right)$ is less than 0.5 . Extremely small currents were measured for drogue \#6. Except for drogues \#2 and $\# 6$, the ratios of the variance of the difference between the observed drogue velocities and the computed currents to the variance of the observed drogue velocities $\gamma_{1}$ are below 1.3 (below 0.7 for six drogues). In scenario TR901102 (on Nov. 2, 1990), a $2.4 \mathrm{~m} \mathrm{~s}^{-1}$ south-western wind prevailed. Six drogues were released at $2 \mathrm{~m}$ and four at $5.0 \mathrm{~m}$. Good simulations were obtained, and all $\gamma_{1}$ values were below 0.9 except for one drogue.

It is observed from these figures that for many drogues the model simulated trajectories were very close to those from the field observation, while for some drogues there was an angle within them. As pointed out in the description of trajectory model, two particles released in the same location may not follow the same path due to the turbulence in the current field. Therefore, the comparison between observed and simulated trajectories that do not coincide may also be considered as a good comparison. A quantitative criterion, which is not available in the literature, was established with the help of the trajectory model using the random-walk approach. It can also be clearly explained by using the conventional advection-diffusion model, i.e., for the movement of the cloud of particles,

$$
\frac{\partial \mathrm{P}}{\partial \mathrm{t}}=-\mathrm{u}_{\mathrm{p}} \frac{\partial \mathrm{P}}{\partial \mathrm{x}}-\mathrm{v}_{\mathrm{p}} \frac{\partial \mathrm{P}}{\partial \mathrm{y}}+\mathrm{K}_{\mathrm{h}} \frac{\partial^{2} \mathrm{P}}{\partial \mathrm{x}^{2}}+\mathrm{K}_{\mathrm{h}} \frac{\partial^{2} \mathrm{P}}{\partial \mathrm{y}^{2}}
$$

where $P$ is the "concentration" of particles. Supposing that a 100 unit particle is continuously released at one location, the contours will present the most likely distribution for the movement of particles released at this location.

Fig. 7(a) shows the trajectories (open circle) of 1000 drogues released at the same point, i.e., the first point in scenario TR900620 using the randomwalk approach. The concentration at each mesh could be calculated by adding the number of drogues located in this mesh. The solid circles are presented for comparison purposes. Contours from the advection-diffusion modelling are shown in Fig. 7(b). It is observed that both methods provide similar results. It is important to determine a standard value of $\gamma_{1}$ for model verification from the random modelling. Table 4 shows the mean, minimum and maximum values of $\gamma_{1}$ under the dispersion coefficients of $0.1,1.0$ and $5.0 \mathrm{~m}^{2} \mathrm{~s}^{-1}$. The typical values for lakes are 1-5 m² s-1 (Wu et al., 1987; Elzawahry, 1985). The value of $\gamma_{1}$ increases with increasing values of dispersion coefficients. The mean $\gamma_{1}$ could be 1.65 when the coefficient is $5.0 \mathrm{~m}^{2}$ $\mathrm{s}^{-1}$. Then if the coefficient for any comparison is below 1.65, the simulation is acceptable. In this sense, most of the simulations (54 out of 62) listed in Tables 2 and 3 are acceptable. 
Table 2. Comparison of drogue measurements and model simulations (Group 1)

\begin{tabular}{|c|c|c|c|c|c|c|c|c|c|c|}
\hline Scenario & $\#$ & $\begin{array}{r}D \\
(\mathrm{~m})\end{array}$ & $\begin{array}{r}u_{d} \\
\left(\mathrm{~cm} \mathrm{~s}^{-1}\right)\end{array}$ & $\begin{array}{r}v_{d} \\
\left(\mathrm{~cm} \mathrm{~s}^{-1}\right)\end{array}$ & $\begin{array}{r}u_{c} \\
\left(\mathrm{~cm} \mathrm{~s}^{-1}\right)\end{array}$ & $\begin{array}{r}v_{c} \\
\left(\mathrm{~cm} \mathrm{~s}^{-1}\right)\end{array}$ & $a$ & $\gamma_{1}$ & $\gamma_{2}$ & $\gamma_{3}$ \\
\hline \multirow[t]{9}{*}{ TR900620 } & 1 & 2.0 & -3.94 & 4.03 & -5.41 & 3.69 & -0.0106 & 0.4792 & 1.3062 & 0.4155 \\
\hline & 2 & 2.0 & -1.92 & 0.25 & -4.84 & 3.33 & -0.0207 & 2.1014 & 3.2256 & 1.1467 \\
\hline & 3 & 2.0 & -0.42 & 1.94 & -1.81 & 1.41 & -0.0087 & 1.3755 & 1.3733 & 1.1467 \\
\hline & 4 & 2.0 & -1.93 & 2.74 & -3.49 & 2.42 & -0.0080 & 0.3303 & 1.5513 & 0.1826 \\
\hline & 5 & 2.0 & -5.31 & 0.56 & -3.25 & 2.24 & -0.0002 & 0.3092 & 1.0079 & 0.3099 \\
\hline & 6 & 6.5 & -0.33 & -0.16 & -3.25 & 2.24 & -0.0227 & 14.8716 & 10.8369 & 4.6807 \\
\hline & 7 & 2.0 & -6.03 & 4.53 & -3.35 & 2.28 & 0.0173 & 0.2541 & 0.5902 & 0.1395 \\
\hline & 8 & 2.0 & -1.68 & 1.22 & -3.06 & 2.07 & -0.0100 & 0.6110 & 2.4599 & 0.1516 \\
\hline & 9 & 6.5 & -4.53 & -1.11 & -3.07 & 2.07 & -0.0093 & 0.7468 & 1.3579 & 0.7161 \\
\hline \multirow[t]{9}{*}{ TR900628 } & 1 & 6.5 & 3.83 & -4.52 & -5.39 & 2.84 & -0.0399 & 3.5757 & 1.0655 & 1.7029 \\
\hline & 2 & 2.0 & -10.39 & 5.82 & -8.50 & 4.43 & 0.0075 & 0.0579 & 0.8224 & 0.0389 \\
\hline & 3 & 2.0 & -7.38 & 6.66 & -7.34 & 3.98 & 0.0060 & 0.1100 & 0.8392 & 0.1035 \\
\hline & 4 & 6.5 & 1.28 & -4.75 & -7.34 & 3.98 & -0.0428 & 5.8159 & 2.2116 & 2.7097 \\
\hline & 5 & 2.0 & -2.87 & -0.56 & -5.12 & 2.88 & -0.0122 & 1.3191 & 1.8446 & 1.0366 \\
\hline & 6 & 2.0 & -1.49 & -2.26 & -5.75 & 3.14 & -0.0232 & 5.5217 & 3.8904 & 3.0700 \\
\hline & 7 & 2.0 & -1.32 & 2.93 & -4.91 & 2.58 & -0.0080 & 1.2718 & 1.8341 & 0.8495 \\
\hline & 8 & 2.0 & -6.32 & 5.50 & -5.61 & 3.00 & 0.0077 & 0.1367 & 0.7645 & 0.1117 \\
\hline & 9 & 2.0 & -4.97 & 5.55 & -5.39 & 2.84 & 0.0052 & 0.2090 & 0.8244 & 0.2046 \\
\hline \multirow[t]{10}{*}{ TR900920 } & 1 & 5.0 & -0.86 & 0.34 & 1.68 & -1.87 & -0.0111 & 6.7133 & 2.6417 & 3.4104 \\
\hline & 2 & 2.0 & 2.17 & -3.94 & 5.29 & -5.74 & -0.0117 & 1.1069 & 2.0453 & 0.8052 \\
\hline & 3 & 2.0 & 3.48 & -2.03 & 1.84 & -1.60 & 0.0018 & 0.3576 & 0.9199 & 0.3511 \\
\hline & 4 & 5.0 & 2.54 & -1.97 & 0.04 & 0.25 & 0.0111 & 1.0699 & 0.5357 & 0.5258 \\
\hline & 5 & 2.0 & 5.18 & 0.57 & 4.07 & -4.52 & -0.0102 & 1.2501 & 1.3967 & 1.1013 \\
\hline & 6 & 2.0 & 3.77 & -4.61 & 4.03 & -4.55 & -0.0013 & 0.1034 & 1.0624 & 0.1014 \\
\hline & 7 & 5.0 & 0.98 & -2.93 & -0.47 & 0.24 & 0.0107 & 1.2100 & 0.6897 & 0.7638 \\
\hline & 8 & 2.0 & 1.75 & -4.32 & 2.45 & -2.75 & 0.0002 & 0.6309 & 0.9888 & 0.6307 \\
\hline & 9 & 2.0 & 2.70 & -2.89 & 3.50 & -3.82 & -0.0035 & 0.3836 & 1.2977 & 0.3501 \\
\hline & 10 & 5.0 & 1.17 & -1.97 & 0.39 & -0.42 & 0.0059 & 0.6748 & 0.6400 & 0.4554 \\
\hline
\end{tabular}

(a)

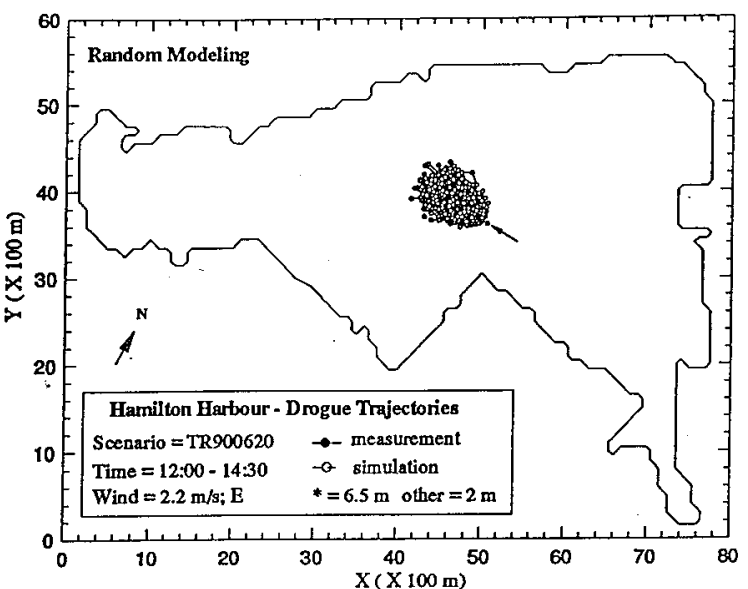

(b)

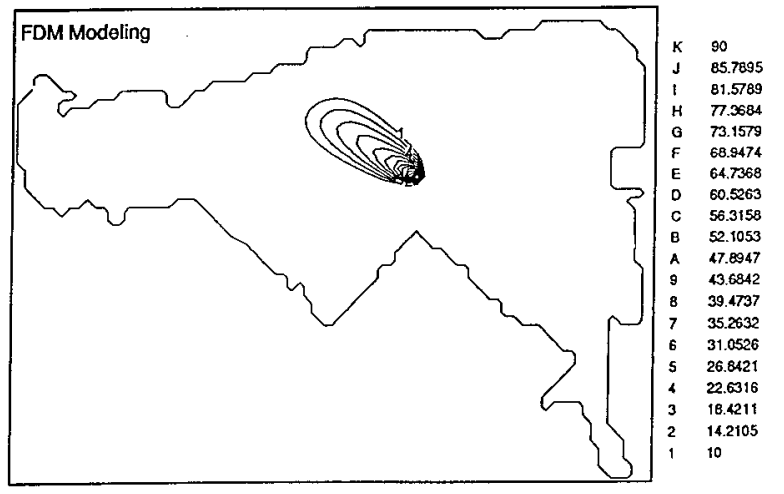

Figure 7. Experiments on the trajectory predictions: (a) movement of 1000 particles released once at the first drogue location in Scenario TR900620 in Hamilton Harbour, using the trajectory prediction model coupled with a Monte-Carlo random-walk approach. (b) contours of equal concentration for a emission of the pollutant (equivalent to a cloud of particles) from the first drogue location in Scenario TR900620, using finite difference advection-diffusion model. 
Table 3. Comparison of drogue measurements and model simulations (Group 2)

\begin{tabular}{|c|c|c|c|c|c|c|c|c|c|c|}
\hline Scenario & \# & $\begin{array}{r}D \\
(\mathrm{~m})\end{array}$ & $\begin{array}{r}u_{d} \\
\left(\mathrm{~cm} \mathrm{~s}^{-1}\right)\end{array}$ & $\begin{array}{r}v_{d} \\
\left(\mathrm{~cm} \mathrm{~s}^{-1}\right)\end{array}$ & $\begin{array}{r}u_{c} \\
\left(\mathrm{~cm} \mathrm{~s}^{-1}\right)\end{array}$ & $\begin{array}{r}v_{c} \\
\left(\mathrm{~cm} \mathrm{~s}^{-1}\right)\end{array}$ & $a$ & $\gamma_{1}$ & $\gamma_{2}$ & $\gamma_{3}$ \\
\hline \multirow[t]{12}{*}{ TR900927 } & 1 & 5.0 & -0.45 & -0.02 & 0.72 & -1.52 & 0.0102 & 2.5806 & 1.0010 & 2.2026 \\
\hline & 2 & 2.0 & 0.66 & -5.39 & 2.65 & -5.34 & 0.0141 & 0.2258 & 1.0750 & 0.1803 \\
\hline & 3 & 2.0 & 2.91 & -2.19 & 0.64 & -1.04 & -0.0108 & 0.4987 & 0.8992 & 0.4347 \\
\hline & 4 & 5.0 & 1.72 & -0.12 & -0.36 & 0.84 & -0.0093 & 1.6564 & 0.8738 & 1.4583 \\
\hline & 5 & 2.0 & 3.87 & -3.26 & 1.81 & -3.72 & -0.0047 & 0.2717 & 0.9665 & 0.2661 \\
\hline & 6 & 2.0 & 2.02 & -5.11 & 1.47 & -3.17 & -0.0001 & 0.1795 & 0.9994 & 0.1795 \\
\hline & 7 & 5.0 & 1.36 & -3.70 & -0.21 & 0.25 & -0.0092 & 1.1565 & 0.9702 & 1.1157 \\
\hline & 8 & 2.0 & 2.16 & -0.96 & 1.66 & -3.55 & 0.0074 & 1.4303 & 1.1418 & 1.3853 \\
\hline & 9 & 2.0 & 0.58 & 2.81 & 2.16 & -4.41 & 0.0264 & 4.7111 & 1.0466 & 4.2659 \\
\hline & 10 & 2.0 & 2.92 & -0.59 & 1.93 & -3.86 & 0.0104 & 1.0452 & 1.0723 & 0.9902 \\
\hline & 11 & 5.0 & 0.46 & -1.93 & 0.24 & -0.49 & 0.0087 & 0.7923 & 0.9621 & 0.7281 \\
\hline & 12 & 2.0 & 1.54 & -2.46 & 1.44 & -2.87 & -0.0012 & 0.2233 & 0.9807 & 0.2220 \\
\hline \multirow[t]{12}{*}{ TR901031 } & 1 & 5.0 & -2.75 & 0.52 & -0.99 & 0.57 & -0.0067 & 0.4299 & 0.7988 & 0.3453 \\
\hline & 2 & 2.0 & -3.84 & -1.16 & -3.47 & 1.99 & 0.0146 & 0.6792 & 1.3765 & 0.6336 \\
\hline & 3 & 2.0 & -6.03 & 1.22 & -2.72 & 1.58 & -0.0137 & 0.4486 & 0.8341 & 0.3905 \\
\hline & 4 & 5.0 & -3.96 & 0.31 & -0.09 & 0.06 & -0.0165 & 0.9707 & 0.7985 & 0.7804 \\
\hline & 5 & 2.0 & -8.10 & 1.34 & -3.55 & 2.04 & -0.0173 & 0.3519 & 0.8147 & 0.2856 \\
\hline & 6 & 2.0 & -5.02 & -0.71 & -2.49 & 1.44 & 0.0011 & 0.4711 & 1.0187 & 0.4752 \\
\hline & 7 & 5.0 & -3.56 & -1.06 & 0.06 & -0.01 & -0.0091 & 1.0275 & 0.8864 & 0.9097 \\
\hline & 8 & 2.0 & -2.34 & 1.35 & -1.43 & 0.88 & -0.0059 & 0.3694 & 0.8409 & 0.3309 \\
\hline & 9 & 2.0 & -3.13 & 1.08 & -2.85 & 1.64 & 0.0018 & 0.0790 & 1.0617 & 0.0794 \\
\hline & 10 & 2.0 & -3.66 & 2.18 & -1.88 & 1.11 & -0.0123 & 0.2993 & 0.7412 & 0.2173 \\
\hline & 11 & 5.0 & -0.99 & 0.55 & 0.00 & 0.01 & -0.0046 & 0.9957 & 0.9080 & 0.9035 \\
\hline & 12 & 2.0 & -5.07 & 1.54 & -2.51 & 1.43 & -0.0110 & 0.2708 & 0.8106 & 0.2117 \\
\hline \multirow[t]{10}{*}{ TR901102 } & 1 & 5.0 & 3.59 & -0.05 & 1.86 & 0.41 & -0.0007 & 0.3884 & 1.0328 & 0.3955 \\
\hline & 2 & 2.0 & 4.70 & -1.12 & 6.46 & 1.05 & -0.0033 & 0.5594 & 1.1520 & 0.4681 \\
\hline & 3 & 2.0 & 6.63 & 0.06 & 5.46 & 0.91 & -0.0033 & 0.1819 & 1.0967 & 0.1755 \\
\hline & 4 & 5.0 & 4.19 & -0.48 & 0.20 & 0.04 & 0.0022 & 0.9210 & 0.9300 & 0.8570 \\
\hline & 5 & 2.0 & 5.82 & -0.19 & 5.67 & 0.87 & -0.0016 & 0.2933 & 1.0599 & 0.2852 \\
\hline & 6 & 5.0 & 3.96 & 3.77 & -0.61 & -0.03 & 0.0010 & 1.1575 & 0.9736 & 1.1270 \\
\hline & 7 & 2.0 & 7.56 & 3.67 & 4.53 & 0.71 & 0.0002 & 0.2840 & 0.9947 & 0.2818 \\
\hline & 8 & 2.0 & 6.19 & 1.87 & 5.26 & 0.77 & -0.0017 & 0.1697 & 1.0589 & 0.1775 \\
\hline & 9 & 5.0 & 5.15 & 1.08 & 0.22 & 0.03 & 0.0074 & 0.9474 & 0.8435 & 0.7997 \\
\hline & 10 & 2.0 & 8.82 & -0.02 & 3.95 & 0.62 & 0.0033 & 0.3567 & 0.9226 & 0.3262 \\
\hline
\end{tabular}

\section{VERIFICATION WITH WATER LEVEL DATA}

The water level change in a lake may be induced by the wind (wind-induced set-up), in/outflows, precipitation, and evaporation, etc. For short periods, the wind-induced change to water level is predom-

Table 4. Theoretical value of $\gamma_{1}$ from random walk modeling

\begin{tabular}{|cccc|}
\hline $\begin{array}{c}\mathrm{K}_{\mathrm{h}} \\
\left(\mathrm{m}^{2} \mathrm{~s}^{-1}\right)\end{array}$ & Mean & Min & Max \\
\hline 0.1 & 0.099 & 0.002 & 0.579 \\
1.0 & 0.555 & 0.016 & 5.429 \\
5.0 & 1.651 & 0.073 & 17.29 \\
\hline
\end{tabular}

inant for most lakes except for some small lakes with highly variable in/outflows. The magnitude of wind-induced water level change depends on the wind speed and fetch or size of the lake. For example, in Lake Ontario (300 km x $80 \mathrm{~km})$, there is a $12 \mathrm{~cm}$ difference of water level between the two ends of the basin for a $10 \mathrm{~m} \mathrm{~s}^{-1}$ westerly wind over several hours. It was found from the field data in Hamilton Harbour that the water level change was much higher than expected (for such a small size basin). These large changes in water elevation are due to Lake Ontario (Wu et al. 1996).

To confirm the above observation and for verifying the model, the scenario HH910814 (Aug. 14-16, 
(a)

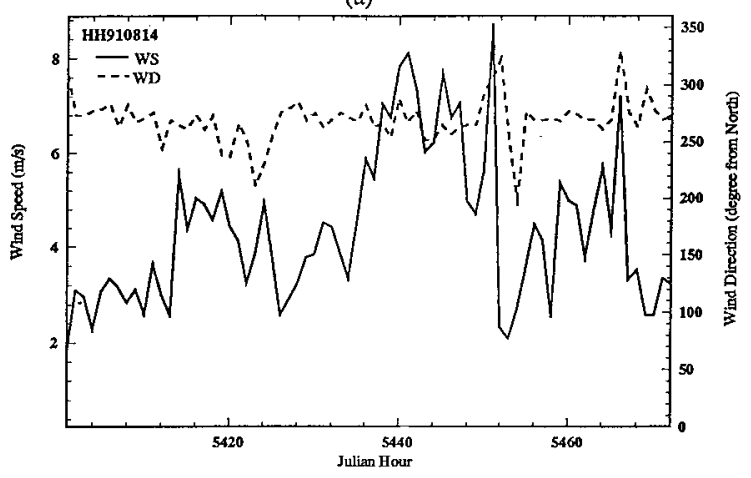

(b)

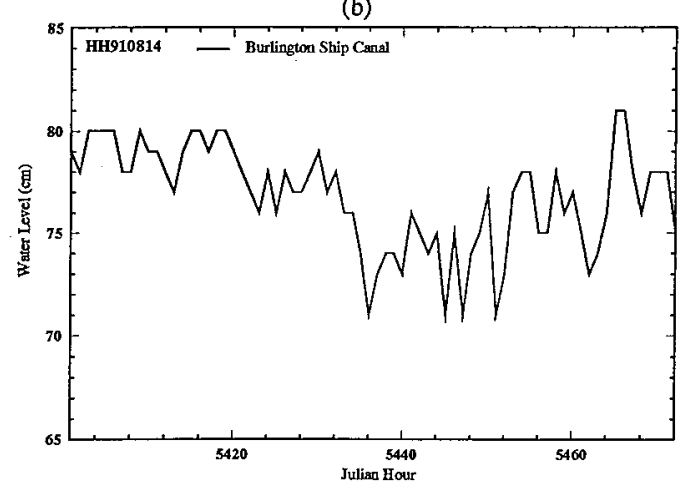

Figure 8. Time series of (a) wind speed and direction, (b) water level at Burlington Ship Canal during 14-16 August 1991, Hamilton Harbour.
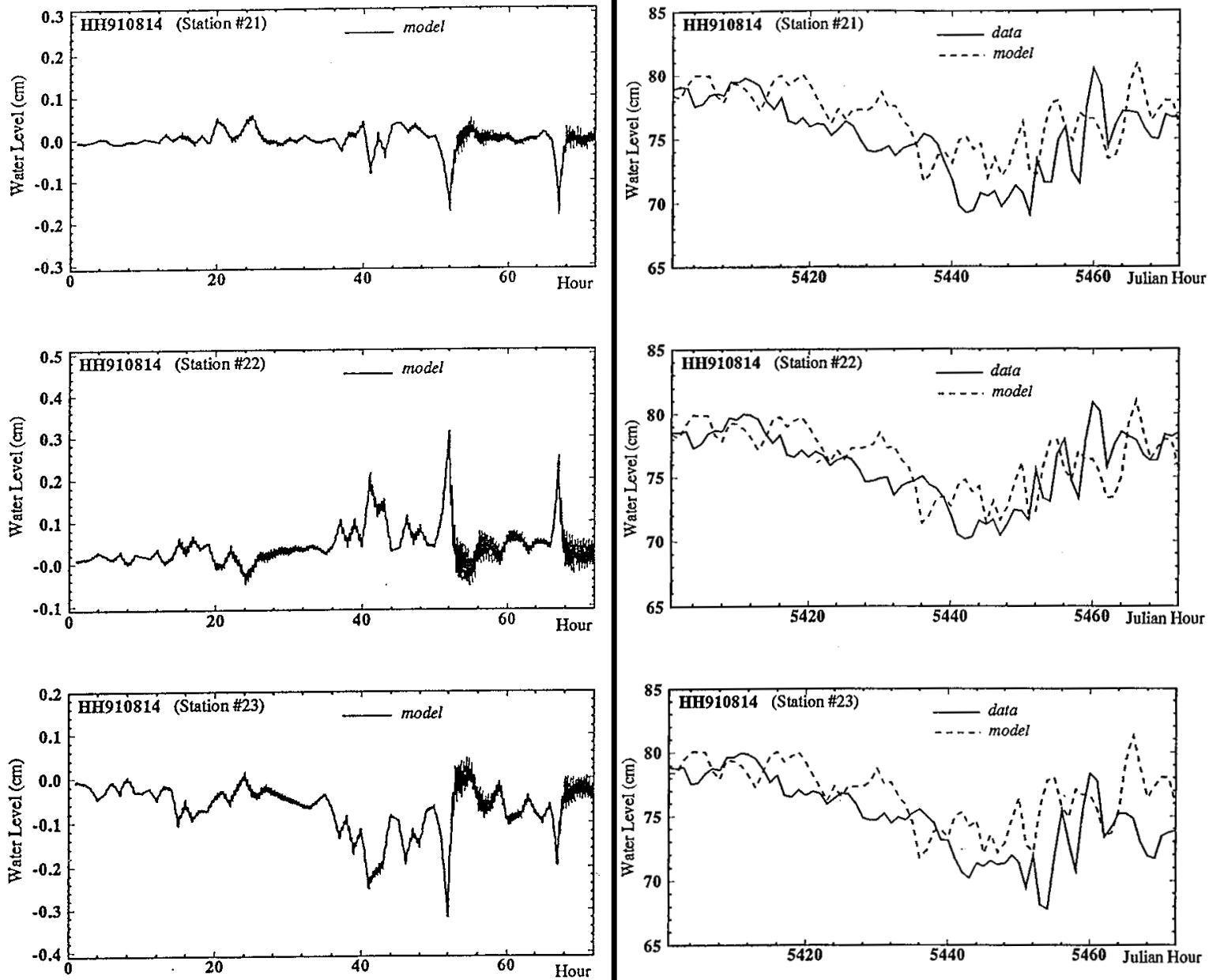

Figure 9. Simulated water level at three stations \#21, \#22 and \#23 in Hamilton Harbour during 14-16, August 1991. The influence of Lake Ontario through Burlington Ship Canal was excluded in the model.

Figure 10. Simulated (dash line) and observed (solid line) water level at three station \#21, \#22, \#23 in Hamilton Harbour during 14-16 August, 1991. 
1991) was simulated. This was a three-day west windstorm, with the wind speed varying between 2 and $9 \mathrm{~m} \mathrm{~s}^{-1}$, as shown in Fig. 8(a). The water level time history at the Burlington Ship Canal during this period is presented in Fig. 8(b). The water level change was between 1-8 $\mathrm{cm}$ over three days. About an $8 \mathrm{~cm}$ decrease in water level occurred in a couple of hours during the second day, when the wind increased from 2 to $9 \mathrm{~m} \mathrm{~s}^{-1}$.

At first, the water level change at Burlington Ship Canal was not included in the simulation. As expected, the water level changes about 0.1-0.5 $\mathrm{cm}$ are due to local wind change (Fig. 9). The water levels at the stations \#21 and \#23 being in the east side of Hamilton Harbour are in phase while the water level at \#22 being in the west side of the Harbour is out of phase. Then, the water level change in the canal was included as a boundary condition in the simulation. Fig. 10 presents the simulations (dashed-line), and the field measurements (solid line) at three stations (stations \#21, \#22, \#23, Fig. 1). The simulations are in good agreement with the measurements. The water level changes are as high as $10 \mathrm{~cm}$. In conclusion, the influence of Lake Ontario must be included in predicting the water level change in Hamilton Harbour.

\section{CONCLUSIONS}

A three-dimensional hydrodynamic model was developed and used to simulate the currents and water levels in Hamilton Harbour. The model was verified using field data collected during the 1990 and 1991 field seasons. Point-by-point comparisons of currents between model and data are one of the most difficult tasks in model verification in the lakes and estuaries. The agreement between observations and simulations was not statistically satisfactory, in most cases, because of the local wind field, complicated thermal structure and sub-grid turbulence. One scenario was selected in Hamilton Harbour, for which the comparison was partially satisfactory. The distribution of wind field over such a small Harbour may be complicated and can significantly affect the current distribution.

Comparisons between observed and simulated drogue trajectories are promising. With the help of a quantitative criterion established using the random-walk approach, it is concluded that for an average dispersion coefficient of $5.0 \mathrm{~m}^{2} \mathrm{~s}^{-1}$ the value of $\gamma_{1}$ less than 1.65 for the simulation, is acceptable. Accordingly, 54 drogues out of total 62 were well simulated. By using the water level changes in the Burlington Ship Canal, the model predictions were validated with the measurements at three water level stations in the Harbour. The simulations were found to be in good agreement with the field data.

In conclusion, the model verification reported in this paper demonstrates that the three-dimensional hydrodynamic model can simulate the main features of the water currents and level changes in Hamilton Harbour.

\section{ACKNOWLEDGEMENTS}

The present work was financially supported by the Tri-Council (MRC, NSERC, SSHRC) Ecosystem Research Program, and the National Science and Engineering Research Council (NSERC) Grant No. OGPO157914.

\section{REFERENCES}

Bennett, J.R. and Clites, A.H. (1987), Accuracy of trajectory calculation in a finite difference circulation model, J. Comp. Phys. 68, 272-282.

Boyce, F.M. and Chiocchio, F. (1991), Drogue measurements - Hamilton Harbour 1990, National Water Research Institute (NWRI), CCIW, Technical Note, No. LRB-91-TN-08.

Elzawahry, A.E. (1985), Advection, diffusion and settling in the coastal zone of Lake Erie, Ph.D. Dissertation, McMaster University.

James, W. and Eid, B. (1978), A three-dimensional model of Hamilton Harbour incorporating spatial distribution of transient surface drag, J. Civ. Eng. Can. 5, 479-488.

Koutitas, C.G. and Gousidou-Koutita, M. (1986), A comparative study of three mathematical models for windgenerated circulation in coastal areas, Coastal Eng. 10, 127-138.

Leendertse, J.J. and Liu, S.K. (1977), A three-dimensional model for estuaries and coastal seas: Vol. IV, Turbulent energy computation, The RAND Corporation, R-2187-OWRT.

MOE, (1974), Hamilton Harbour study, Water Resources Branch, Toronto.

MOE, (1992), Remedial action plan for Hamilton Harbour: environmental conditions and problem definitions 
(RAP stages $1 \& 2$ ).

Murthy, C. R., Simons, T. J. and Lam, D. C. L. (1986), Dynamic and transport modeling of the Niagara River plume in Lake Ontario, Rapp. P.-v. Reun. Con. int. Explor. Mer, 186, 150-164.

Rasmussen, H. and Badr, H.M. (1979), Validation of numerical models of the unsteady flow in lakes, Appl. Math. Modelling, 3, 416-420.

Schwab, D. J., Clites, A. H. and Murthy, C.R. (1989), The effect of wind on transport and circulation in Lake St.Clair, J. Geophy. Res. 94, 4947-4958.

Tsanis, I.K. (1989), Simulation of wind-induced water currents, J. Hydr. Eng. (ASCE), 115, 1113-1134.

Tsanis, I.K., Masse, A., Murthy, C.R., and Miners, K. (1990), Summer circulation in the Kingston Basin, Lake Ontario, J. Great Lakes Res. 17, 57-73.

Wu, J., Pu, P., Wang, Q.Q. and Huang, Q. (1987), Features of current and horizontal diffusion fields at Dapu River mouth in Lake Tai, International Symposium in Lake Tai and Lake Biwa, 21-25.

Wu, J. (1993), An integrated hydrodynamic/pollutant transport model for the nearshore areas of the Great Lakes and their tributaries, Ph.D. thesis, Department of Civil Engineering, McMaster University, Canada.

Wu, J. and Tsanis, I.K. (1995), Numerical study of wind-induced water currents, J. Hydr. Eng. (ASCE), 121, 388395.

Wu, J., Tsanis, I.K. and Chiocchio F. (1996), Observed currents and water levels in Hamilton Harbour, J. Great Lakes Res. 22, 224-240. 